\title{
Crystallization of Polyethylenes Containing Chlorines: Precise vs Random Placement
}

\author{
R. G. Alamo, ${ }^{*}{ }^{\dagger}$ K. Jeon, ${ }^{\dagger}$ R. L. Smith, ${ }^{\dagger}$ E. Boz, ${ }^{\ddagger}$ K. B. Wagener,${ }^{\ddagger}$ and M. R. Bockstaller ${ }^{\S}$ \\ Department of Chemical and Biomedical Engineering, FAMU-FSU College of Engineering, \\ 2525 Pottsdamer St., Tallahassee, Florida 32310-6046; The George and Josephine Butler Polymer \\ Research Laboratory, Department of Chemistry, University of Florida, Gainesville, \\ Florida 32611-7200; and Department of Materials Science and Engineering, Carnegie Mellon \\ University, 5000 Forbes Ave., Pittsburgh, Pennsylvania 15213
}

Received May 23, 2008; Revised Manuscript Received June 12, 2008

\begin{abstract}
The crystallization behavior and crystalline structure of a series of chlorine-containing polyethylenes (PEs) with either a random or a precise placement of the $\mathrm{Cl}$ atom on each and every 21st, 19th, 15th, and 9th backbone carbon have been studied by DSC, NMR, Raman spectroscopy, WAXD, SAXS and AFM in samples cooled from the melt at $1{ }^{\circ} \mathrm{C} / \mathrm{min}$. All precision Cl-substituted PEs crystallize as homopolymers based on their DD/MAS solid-state ${ }^{13} \mathrm{C}$ NMR spectra that reveal a uniform distribution of the content of halogen between crystalline and noncrystalline regions. In addition, unique WAXD crystallographic patterns that differ from those of the linear PE and random polymers, relatively large crystal thicknesses, and sharp crystallization and melting peaks also support this homopolymer pattern in precision systems. In contrast, a high concentration of $\mathrm{Cl}$ in the noncrystalline regions in the case of the random systems suggest that the crystallization process for randomly substituted samples is being led by the selection of the most crystalline sequences, resulting in broad thermal transitions and lower crystallinities. Increasing chlorine content in both precision and random systems decreases crystallinity, melting temperature, heat of fusion, and crystallite thicknesses suggesting that $\mathrm{Cl}$ atoms are defects that hinder the crystallization of these polyolefins. Both systems are found to exhibit a lamellar crystalline morphology. Precision substituted polyethylenes form long, straight, and stacked lamellae with axialitic (PE21Cl, $\mathrm{PE} 19 \mathrm{Cl}$, and $\mathrm{PE} 15 \mathrm{Cl})$ or spherulitic (PE9Cl) organization as typical of homopolymers of similar molar mass. In contrast, the lamellae of random analogs are curved and more segmented as found in other PE random copolymers. The distribution of $\mathrm{Cl}$ within the crystalline regions of systems with precision substitution is strongly affected by the sequence length of the methylene groups. Packing around the substitution point of $\mathrm{PE} 21 \mathrm{Cl}, \mathrm{PE} 19 \mathrm{Cl}$, and $\mathrm{PE} 15 \mathrm{Cl}$ render nearly all-trans conformations and asymmetric $\mathrm{Cl}$ distribution, while close staggering of $\mathrm{Cl}$ atoms in the crystals of $\mathrm{PE9Cl}$ exert conformational distortions as observed by a strong increase of TG conformers in the Raman spectra.
\end{abstract}

\section{Introduction}

The impact of the production of polyolefins and in particular polyethylenes in the world economy is undeniable. To a large extent this is due to the role of polymer crystallinity on properties and the ability to tune the crystalline fraction and the semicrystalline morphology by copolymerization of ethylene with a large variety of polar and nonpolar comonomers. It is now well-known that not only the type and content of co-units impact the copolymer properties but to a very large extent the distribution of the co-units also has a major role in the final material properties. ${ }^{1-3}$ The fundamental principles that allow for the choice of microstructures and processes to suit specific properties are usually formulated based on the behavior of models of polyethylenes with well-defined microstructures. To this end, products synthesized with metallocene catalysts have played a major role. ${ }^{4,5}$ Materials have been developed ranging from statistical random copolymers to stereoblocky elastomeric types exemplifying the ability of new synthetic strategies to tailor structures and properties of polyolefins by a suitable choice of the coordination catalyst precursor. ${ }^{4,6,7}$

The effect of a comonomer, added as an irregularity in the polyethylene chain, on decreasing crystallinity depends on the ability of the co-unit for cocrystallization with the ethylene units. While small side groups such as halogens, oxygen, and the

\footnotetext{
* Corresponding author. Email: alamo@eng.fsu.edu.

FAMU-FSU College of Engineering.

$\$$ Carnegie Mellon University.

¿niversity of Florida.
}

methyl branch can be partially incorporated into the orthorhombic polyethylene lattice, longer branches are excluded from the PE crystals..$^{8-11}$ In addition, the composition and distribution of substituents and branches along the polyethylene chain are also important factors to the crystalline behavior. Using olefin methatesis polycondensation, special families of polyolefins have been recently synthesized with precise substitution of a $\mathrm{H}$ of the $\mathrm{PE}$ backbone for a halogen atom $(\mathrm{F}, \mathrm{Cl}$, or $\mathrm{Br})$ on each and every 9 th, 15 th, 19 th, or 21 st carbon. ${ }^{12-14}$ These families are suitable model systems to study the effect of precise placement of a side group on the crystallization of polyethylenes. The level of control in the placement of the substituent given by this synthetic route is unprecedented and allows one to derive relationships between polymer primary structure and physical properties in these precision ethylene vinyl halide-type polymers.

A major conclusion from our previous work on the crystallization behavior of precision PEs with a ketone group or a $\mathrm{F}$, $\mathrm{Cl}$, or $\mathrm{Br}$ atom on every 19 th backbone carbon is that these polyolefins crystallize as homopolymers. ${ }^{15}$ Despite the lack of control in tacticity, the crystallization is driven by the accommodation of the substituent in a close-packing arrangement of chain segments in a symmetric lattice. ${ }^{15}$ Each precision system, distinguished by the substitution type, is a unique polyolefin with crystalline properties characterized by the level of strain induced by the incorporation of the substituent in the lattice. A quantitative correlation was found between the halogen's van der Waals radius and the degree to which the orthorhombic lattice of the linear PE chain can tolerate atomic hydrogen substitution at a level of $5.3 \mathrm{~mol} \% .^{15}$ 
Table 1. Molecular and Thermal Characterization of Precision and Random Chlorine-Containing Polyethylenes

\begin{tabular}{lclccrrr}
\hline sample & $\begin{array}{c}\text { mol \% } \\
(\mathrm{Cl})^{a}\end{array}$ & distribn & $\begin{array}{c}M_{\mathrm{w}} \times 10^{3} \\
(\mathrm{~g} / \mathrm{mol})^{b}\end{array}$ & $\begin{array}{c}M_{\mathrm{w}} / M_{\mathrm{n}} \\
\left({ }^{\circ} \mathrm{C}\right)^{c}\end{array}$ & $\begin{array}{r}T_{\mathrm{m}} \\
\left({ }^{\circ} \mathrm{C}\right)^{c}\end{array}$ & $\begin{array}{r}\Delta H_{\mathrm{m}} \\
(\mathrm{J} / \mathrm{g})^{c}\end{array}$ \\
\hline $\mathrm{PE}$ & 0 & & 13.1 & 1.26 & 115 & 133 & 238 \\
$\mathrm{PE} 21 \mathrm{Cl}$ & 4.76 & precise & $31.1^{\mathrm{i}}$ & 4.4 & 70 & 81 & 111 \\
$\mathrm{PE} 19 \mathrm{Cl}$ & 5.26 & precise & $22.3^{\mathrm{ii}}$ & 2.2 & 63 & 73 & 105 \\
$\mathrm{PE} 15 \mathrm{Cl}$ & 6.67 & precise & $51.4^{4 i}$ & 1.8 & 54 & 63 & 87 \\
$\mathrm{PE9Cl}$ & 11.11 & precise & $48.7^{\mathrm{ii}}$ & 1.8 & 15 & 41 & 27 \\
$\mathrm{RPE} 21 \mathrm{Cl}$ & 4.76 & random & $118.5^{\mathrm{ii}}$ & 2.2 & 73 & 88 & 98 \\
RPE15Cl & 6.67 & random & $73.6^{\mathrm{ii}}$ & 2.1 & 56 & 71 & 76
\end{tabular}

${ }^{a}$ Content of $\mathrm{Cl}$, in moles of $\mathrm{Cl}$ per 100 backbone carbons. ${ }^{b} \mathrm{i}$, GPC vs PS in THF; ii, GPC vs PE in DCB. ${ }^{c}$ Crystallization peak $\left(T_{\mathrm{c}}\right)$, second melting peak $\left(T_{\mathrm{m}}\right)$, and observed heat of fusion $\left(\Delta H_{\mathrm{m}}\right)$ obtained by DSC at $10{ }^{\circ} \mathrm{C} / \mathrm{min}^{.13,16}$

In the present work, we elucidate the crystallization behavior of a series of Cl-substituted polyethylenes on each and every 9th, 15th, 19th, and 21st carbon. The synthesis of these polymers via acyclic diene metathesis (ADMET) followed by exhaustive hydrogenation, and thermal properties, were reported in a previous work. ${ }^{13}$ The interest in studying similarly constituted precision vinyl chlorides with longer and shorter $\mathrm{CH}_{2}$ spacers than the $18 \mathrm{CH}_{2}$ spacer previously studied, ${ }^{15}$ lies in the progression of crystalline properties expected in the series due to the radically different behavior of PE and PVC at the spacers extremes. While solid solutions are also expected in the crystals developed by precision branched polyethylenes with spacers between $\mathrm{Cl}$ substituents longer than $18 \mathrm{CH}_{2}$ units, the unit cell and the symmetry of the packing should be further affected by the lack of stereospecificity of the side group, or from steric hindrance when the distance is reduced to only few methylene units. Conformational distortions should be more pronounced in this case.

It is thus our objective here to evaluate the effect of increasing chlorine content on the unit cell packing and crystalline structure developed by these unique systems. In addition, the crystallization behavior and crystalline morphology of precision vinyl chloride polymers are compared with data for analogous systems with a matched composition but random chlorine distribution that were synthesized using an analogous ADMET approach. ${ }^{16}$

\section{Experimental Section}

Materials. Four precision polyethylenes with chlorine atoms placed on each and every 9th, 15th, 19th, and 21st backbone carbons have been studied. These polymers are labeled PE9Cl, PE15Cl, $\mathrm{PE} 19 \mathrm{Cl}$, and $\mathrm{PE} 21 \mathrm{Cl}$, where the number corresponds to the precise location of the chlorine atom in the PE backbone. Structurally, they are equivalent to ethylene vinyl chlorides (EVC) with a regular and precise placement of the $\mathrm{Cl}$ atoms. Their repeated structural unit is the following:

$$
\left.-\left[\left(\mathrm{CH}_{2}\right)_{\mathrm{x}}-\mathrm{CH}\right]_{\mathrm{Cl}}^{\mathrm{Cl}}\right]_{\mathrm{n}^{-}}^{-}
$$

with $\mathrm{x}=8,14,18$ or 20

Two additional EVCs with a random chlorine distribution and chlorine mole fraction matching the content in PE15Cl and PE21Cl were also studied. These random systems are labeled $\mathrm{RPE} 15 \mathrm{Cl}$ and $\mathrm{RPE} 21 \mathrm{Cl}$. The synthesis and primary characterization of both precision and random systems have been reported in previous works. ${ }^{13,16}$ The absence of vibrations characteristic of the $\mathrm{C}=\mathrm{C}$ bond in the IR spectra confirm the complete hydrogenation of both sets. Data relevant to the molecular and thermal characterization of these samples are listed in Table 1. Also listed is a narrow fraction of a linear polyethylene (PE) purchased from the Société Nationale Elf d'Aquitaine (S.N.P.A), France. The properties of this linear polyethylene fraction serve as reference for the behavior of the unsubstituted system.

For Raman, NMR, WAXD, SAXS, and DSC measurements, the initial powders were melt pressed within thin Teflon films in $10 \times$
$10 \times 0.5 \mathrm{~mm}^{3}$ molds using a Carver press at temperatures $25-30$ ${ }^{\circ} \mathrm{C}$ higher than the observed final melting. The molten films were slowly cooled at $1{ }^{\circ} \mathrm{C} / \mathrm{min}$ to room temperature $\left(22 \pm 1^{\circ} \mathrm{C}\right)$.

Characterization Techniques. Room temperature Raman spectra were obtained using a Jobin Yvon Horiba LabRAM HR 800 microRaman spectrometer using the $488 \mathrm{~nm}$ line of a coherent I-90 argon ion laser as excitation source with a power of $50 \mathrm{~mW}$. Spectra were collected by exposing the detector for $60 \mathrm{~s}$ and averaging three exposures per spectral window. Fifteen spectral windows were overlapped in the range of $100-3200 \mathrm{~cm}^{-1}$. Spectra as a function of increasing temperature were obtained in a Renishaw Invia Raman microscope in the backscattering configuration with a $50 \times$ objective. The $488 \mathrm{~nm}$ line was used for excitation with a laser power of 25 $\mathrm{mW}$. A film of about $50 \mu \mathrm{m}$ thickness was slowly cooled from the melt to room temperature at $1{ }^{\circ} \mathrm{C} / \mathrm{min}$ and loaded in a Linkam hot stage where the temperature was elevated stepwise, holding for 2 min at each temperature before the measurement.

DD-MAS solid-state ${ }^{13} \mathrm{C}$ NMR spectra were obtained in a Bruker DMX300 spectrometer operating at $75.5 \mathrm{MHz}$ for ${ }^{13} \mathrm{C}$. The experiments were conducted at room temperature using a Bruker solid-state probe for $4 \mathrm{~mm}$ rotors under a MAS frequency of 4000 $\mathrm{Hz}$. The small quantities available for these polymers were placed in the center of the zirconium rotors and the empty spaces filled with Teflon tape. Quantitative single pulse spectra were obtained using a recycle delay of $150-180 \mathrm{~s}$, which was found to be $\sim 5$ times the largest spin-lattice relaxation time for the series. This time ensures full recovery of the magnetization of carbons in amorphous and crystalline environments. Chemical shifts were measured with respect to tetramethylsilane at $0 \mathrm{ppm}$ and using glycine's carbonyl carbon at $173 \mathrm{ppm}$ as external reference. All peak fit analysis were carried out using the software GRAMS from Galactic Corp.

WAXD diffractograms were collected at room temperature on samples crystallized from the melt at $1{ }^{\circ} \mathrm{C} / \mathrm{min}$ using a slit collimated Siemens D-500 diffractometer in a $2 \theta$ range between $5^{\circ}$ and $40^{\circ}$ with a step size of $0.02^{\circ}$. The instrument was calibrated for $d$ spacing with a standard polished piece of polycrystalline quartz, and the film thickness was offset using shims. The diffractogram of molten $\mathrm{PE}$ (at $160^{\circ} \mathrm{C}$ ) and molten $\mathrm{PE} 9 \mathrm{Cl}$ (at 80 ${ }^{\circ} \mathrm{C}$ ) were used to subtract the amorphous halo to determine the degree of crystallinity. These high-temperature WAXDs were collected on a Siemens D500 with an attached Anton Paar HTK high-temperature head.

Small-angle X-ray scattering (SAXS) experiments were performed at $T=298 \mathrm{~K}$ using a Rigaku SAXS apparatus equipped with a Bede microsource and a 2D array detector (diameter primary beam $d=25 \mu \mathrm{m}$, circular cross section). The wavelength of the radiation source was $\lambda=0.154 \mathrm{~nm}(\mathrm{Cu} \mathrm{K \alpha})$ and the scattering vector, $q(q=4 \pi \sin \theta) / \lambda$ (with $2 \theta$ denoting the scattering angle) was calibrated using silver behenate standard. The raw intensity was corrected for its value at the pixel location at the beam stop by a linear extrapolation for the calculation of the correlation function. Corrected SAXS intensities were used to obtain the normalized one-dimensional correlation function of the electron density fluctuations perpendicular to the lamellar stacks according to ${ }^{17}$

$$
\gamma(r)=\frac{\int_{0}^{\infty} q^{2} I_{\mathrm{c}}(q) \cos (q r) \mathrm{d} q}{\int_{0}^{\infty} q^{2} I_{\mathrm{c}}(q) \mathrm{d} q}
$$

Isothermal crystallizations and further melting were followed by DSC using a Perkin-Elmer DSC-7 calibrated with indium and operating under nitrogen flow. The sample mass was about $4 \mathrm{mg}$ and the heating rate $10^{\circ} \mathrm{C} / \mathrm{min}$.

AFM images were collected on $\sim 50 \mu \mathrm{m}$ thick films crystallized with one free surface on a Linkam hot stage by cooling the molten films to room temperature at $1{ }^{\circ} \mathrm{C} / \mathrm{min}$. AFM micrographs were obtained using the environmental JEOL 4210 scanning probe microscope operating at ambient conditions with Olympus single side coated silicon cantilevers (spring constant of $\sim 40 \mathrm{~N} / \mathrm{m}$ and a 


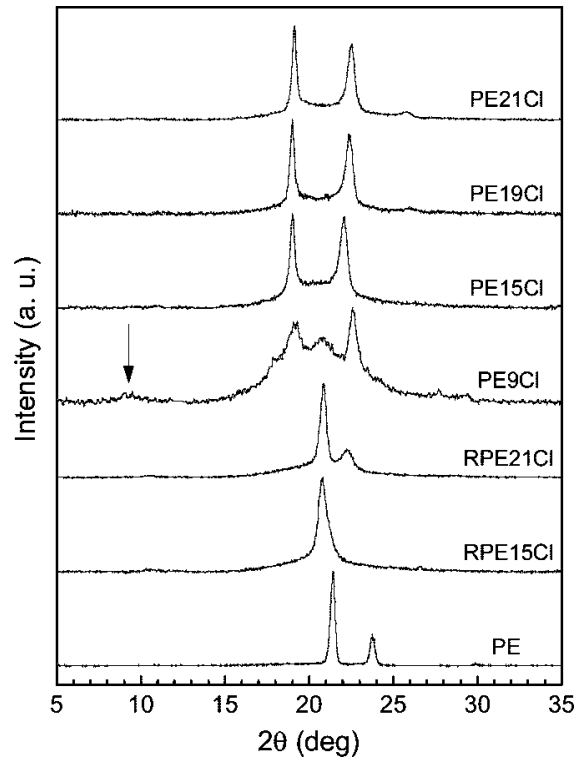

Figure 1. WAXD diffractograms collected at room temperature for samples cooled from the melt to room temperature at $1{ }^{\circ} \mathrm{C} / \mathrm{min}$. Linear polyethylene (PE) and Cl-substituted polyethylenes with precise and random distribution are shown.

Table 2. WAXD Reflections, $d$ Spacings, and Degree of Crystallinity $\left(\mathbf{X}_{\mathrm{c}}\right)$ for Cl-Substituted Polyethylenes with Precision and Random Cl Placement, and Lattice Parameters of the Orthorhombic Lattices

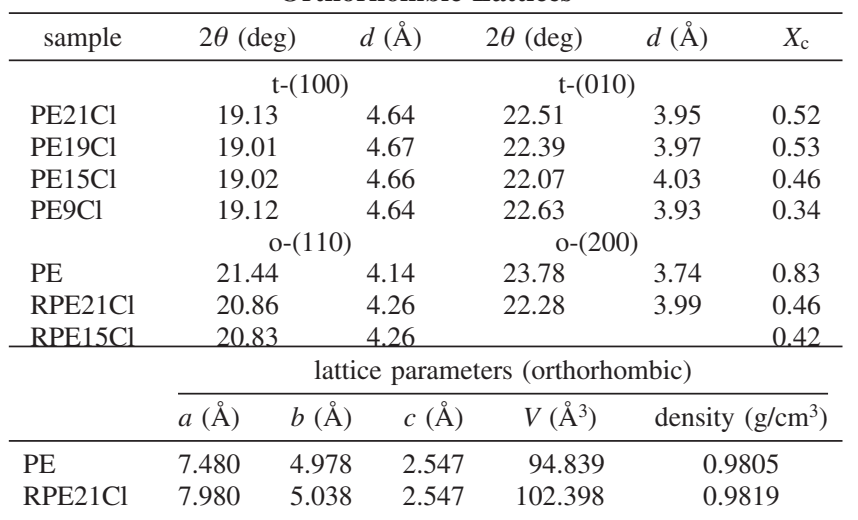

tip radius of less than $10 \mathrm{~nm}$ ) at a resonant frequency of $\sim 300$ $\mathrm{kHz}$. Topographic and phase images were simultaneously collected under ambient conditions in noncontact AC mode at $256 \times 256$ pixel resolution.

\section{Results and Discussion}

WAXD. The crystallization behavior of these polyolefins is first investigated analyzing chain packing patterns inferred from wide-angle X-ray diffractograms (WAXD). These patterns, shown in Figure 1 for samples with precision and random distribution of $\mathrm{Cl}$ atoms, are a fingerprint of the crystallographic symmetry at the most elemental level of aggregation. The $d$ spacing of the main reflections, the parameters for the orthorhombic lattices, and the degree of crystallinity obtained after subtraction of the halo are listed in Table 2. The pattern and parameters of the unsubstituted linear chain (PE) are also given as reference.

The first feature observed in Figure 1 is that the orthorhombic symmetry of the linear PE chain is only maintained in RPE21Cl, the sample equivalent to a model random ethylene vinyl chloride with 4.76 moles of $\mathrm{Cl}$ units per 100 backbone carbons. Analogous to the behavior of chlorinated polyethylenes, ${ }^{8}$ the shift to lower angles of both diffractographic planes of RPE21Cl with respect to the reflections of $\mathrm{PE}$ is consistent with the expansion of the orthorhombic unit cell due to the incorporation of $\mathrm{Cl}$ units in the crystal. As listed in Table 2 the expansion is mainly along the $a$ axis. Increasing the content of $\mathrm{Cl}$ randomly distributed to levels of $\sim 7 \mathrm{~mol} \%$, such as for RPE15Cl, increases the probability of $\mathrm{Cl}$ incorporation in the crystal due to the depletion in the concentration of long continuous methylene sequences and, hence, the need for incorporating shorter sequences to perpetuate crystalline symmetry. The distortions to the orthorhombic lattice by the relatively large $\mathrm{Cl}$ units are such that the WAXD pattern becomes broad and only the most intense 110 reflection prevails, as observed in Figure 1 for RPE15Cl. The single reflection at $20.83^{\circ}$ suggests pseudohexagonal packing and follows the behavior of random chlorinated polyethylenes previously studied, which display broader WAXD reflections with increasing content of $\mathrm{Cl}$ and single peaks for $\mathrm{Cl}$ contents $>5 \mathrm{~mol} \%$. $^{8,18}$ Single WAXD reflections at $21^{\circ}-22^{\circ}$ were also observed in a matched methylbranched PE with a random distribution of side groups ${ }^{10}$ and for random ethylene propylene copolymers. ${ }^{19}$ Clearly, while below a level of random $\mathrm{Cl}$ substitution of $\sim 5 \mathrm{~mol} \%$ the overall intake of $\mathrm{Cl}$ in the crystalline regions does not cause a sufficient perturbation as to make the orthorhombic packing unstable, at higher levels of $\mathrm{Cl}$ or methyl substitution the perturbations to the lattice are more severe. We should also point out that the diffraction peaks of RPE21Cl and RPE15Cl are sharper and the crystallinities higher than those of random ethylene copolymers with the same level of methyl branching ${ }^{10}$ or chlorine pendant groups. ${ }^{8}$ This is due to the limitation of short sequence lengths of RPE21Cl and RPE15Cl. Structurally, RPE21Cl and $\mathrm{RPE} 15 \mathrm{Cl}$ are pseudorandom EVC copolymers because the nature of the starting monomers limits the lower end of the ethylene sequence length distribution to eight continuous $\mathrm{CH}_{2}$ units. $^{16}$

Contrasting the behavior of the random polymers, all precision chlorine-containing polyethylenes pack in crystallographic cells that differ from those found in the linear PE or random systems. WAXD patterns for $\mathrm{PE} 21 \mathrm{Cl}, \mathrm{PE} 19 \mathrm{Cl}$, and $\mathrm{PE} 15 \mathrm{Cl}$ are very similar and characterized by sharp, strong reflections at $\sim 19^{\circ}$ and $\sim 22.5^{\circ}$. Taking as reference a similar diffractogram found in methyl-branched analogues, ${ }^{20}$ this pattern is associated with a triclinic lattice for which reflections at $19^{\circ}$ and $\sim 22.5^{\circ}$ correspond to planes (100) and (010) respectively. In reference to the unsubstituted chain, the drastic change in WAXD patterns of precisely substituted polymers suggests a homopolymer crystallization led by the precise regularity of the substitution, as demonstrated in our previous work. ${ }^{15}$ A change from orthorhombic to a less symmetric unit cell suggests that a reduced order in the packing is needed to facilitate minimum spatial requirements to accommodate the $\mathrm{Cl}$ groups between adjacent molecules in the crystal. With increasing $\mathrm{Cl}$ content in this precision series, the $d$ spacing of the (010) plane shifts from 3.95 to $4.03 \AA$, following the expected incorporation of the halogen in the lattice at contents proportional to the $\mathrm{Cl}$ content in the chain.

The WAXD pattern of PE9Cl does not follow the progressive shift of the (010) reflection to lower angles with increasing $\mathrm{Cl}$ in the precision series. In addition to the major reflections at $19.12^{\circ}$ and $22.63^{\circ}, \mathrm{PE} 9 \mathrm{Cl}$ displays a peak at $\sim 21^{\circ}$ suggesting the coexistence of two polymorphic forms. Thus, it appears that when the distance between $\mathrm{Cl}$ decreases to $\leq 8$ methylenes, the proximity of the $\mathrm{Cl}$ atoms in the lattice exert additional strain barriers for folded chain segments to propagate crystalline symmetry. Furthermore, the lack of stereospecificity of the $\mathrm{Cl}$ atom with respect to adjacent stereo centers may have a stronger impact in perpetuating crystallographic order at this $(11.1 \mathrm{~mol}$ 


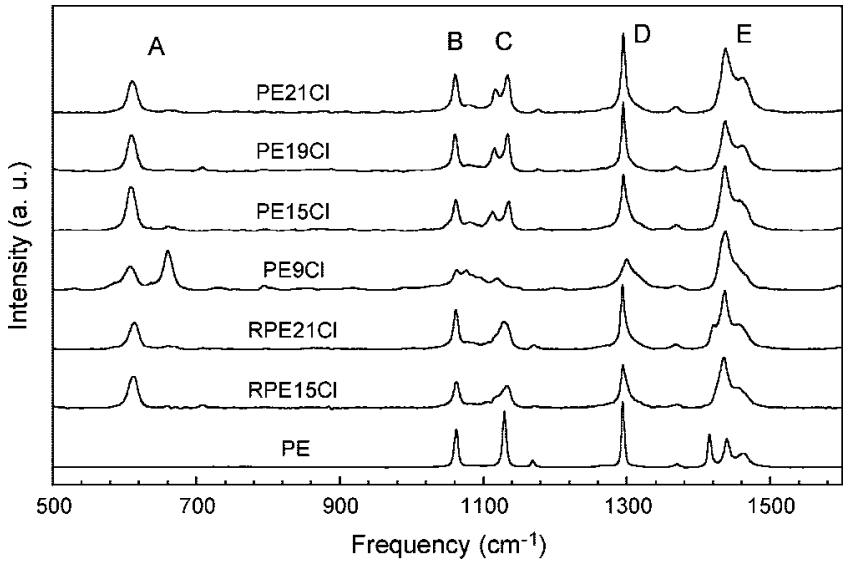

Figure 2. Raman spectra collected at room temperature for samples crystallized from the melt at $1{ }^{\circ} \mathrm{C} / \mathrm{min}$. Linear polyethylene (PE) and $\mathrm{Cl}$-substituted polyethylenes with precise and random distribution are shown. (A) $\mathrm{C}-\mathrm{Cl}$ stretching; (B) antisymmetric $\mathrm{C}-\mathrm{C}$ stretching; (C) symmetric $\mathrm{C}-\mathrm{C}$ stretching; (D) $\mathrm{CH}_{2}$ twisting; and (E) $\mathrm{CH}_{2}$ bending vibration mode.

$\%$ ) and higher levels of precise substitution. After all, the upper substitution limit corresponds to atactic poly(vinyl chloride).

The WAXD patterns of Figure 1 provide direct evidence of the impact of distribution of the substituent in chain organization of substituted polyethylenes at the most fundamental level. We observed from the crystallinity data listed in Table 2 that in reference to the unsubstituted chain, the substitution of $\mathrm{H}$ for $\mathrm{Cl}$ atoms either at a regular distance or randomly restricts the fraction of material that can be crystallized from $83 \%$ to less than $50 \%$. This means that the $\mathrm{Cl}$ atom is a negative perturbation disrupting, albeit not suppressing, PE crystallization. For homopolymers with precise $\mathrm{Cl}$ substitution, the WAXD determined crystallinity scales proportionally to the heat of fusion (listed in Table 1) and inversely to the content of $\mathrm{Cl}$ in the chain.

Raman Spectroscopy. Figure 2 shows room temperature Raman spectra in the internal mode region of the same precision and random polymers. The first region of interest is between 1400 and $1500 \mathrm{~cm}^{-1}$ where precision polymers show two peaks and random and orthorhombic PEs show three bending vibrations. The orthorhombic PE packing requires 2 molecules per cell causing the $\mathrm{CH}_{2}$ bending vibration to split into two components, one at $1416 \mathrm{~cm}^{-1}$ and a second at $1441 \mathrm{~cm}^{-1}$, as observed in the spectra of linear PE and RPE21Cl. Lack of crystal field splitting of the $\mathrm{CH}_{2}$ bending mode in any of the materials with precise $\mathrm{Cl}$ substitution gives further evidence for a different crystalline packing with only one molecule per cell, such as the triclinic form of PE. Specific bands of the amorphous regions, such as the broad one at $1303 \mathrm{~cm}^{-1}$ in the $\mathrm{CH}$ twisting region and the $1080 \mathrm{~cm}^{-1}$ corresponding to the $\mathrm{C}-\mathrm{C}$ skeletal stretching, increase in intensity with increasing $\mathrm{Cl}$, especially in the precision series, reflecting the decrease of crystallinity as the distance between substituents decreases.

While the region of the Raman spectra above $900 \mathrm{~cm}^{-1}$ supports the crystalline features observed by WAXD, Raman bands in the $600-700 \mathrm{~cm}^{-1}$, characteristic of $\mathrm{C}-\mathrm{Cl}$ stretching, are of special interest. Using model compounds, it has been shown that the Raman frequency of the $\mathrm{C}-\mathrm{Cl}$ stretching mode depends on the conformation of the $\mathrm{C}-\mathrm{C}$ bonds in the vicinity of the $\mathrm{C}-\mathrm{Cl}$ bond. ${ }^{21-23}$ The band at $612 \mathrm{~cm}^{-1}$ corresponds to trans - trans (TT) conformers while that at $665 \mathrm{~cm}^{-1}$ is associated with trans-gauche (TG) types of conformations. Thus, these bands are especially useful to obtain a quantitative assessment of the content of gauche conformers in the samples from the ratio of the $665 \mathrm{~cm}^{-1}$ band area over the total TT and $\mathrm{TG}$ areas in this region.

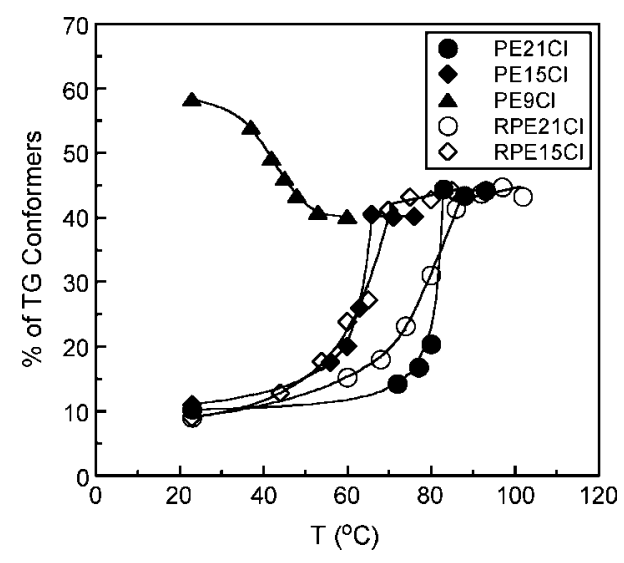

Figure 3. Percentage of TG conformers in $\mathrm{C}-\mathrm{CHCl}-\mathrm{C}$ on heating samples crystallized from the melt at $1{ }^{\circ} \mathrm{C} / \mathrm{min}$. Data are shown for $\mathrm{Cl}$-substituted polyethylenes with precise (filled symbols) and random (open symbols) distribution.

We see in Figure 2 that except for $\mathrm{PE} 9 \mathrm{Cl}$, the content of TG conformers at room temperature for all samples is $9 \pm 2 \%$. The TG content in $\mathrm{PE9Cl}$ at room temperature is $58 \%$, a drastically higher value. To ascertain the distribution of gauche conformers between the amorphous and crystalline region, Raman spectra were collected for each sample as the temperature was raised between ambient and above the melting point of each polymer. Shown in Figure 3 are the results for precision and random samples. In the melt $\sim 44 \%$ of all $\mathrm{C}-\mathrm{CHCl}-\mathrm{C}$ bonds of all samples adopt a TG conformation. However, while for PE21Cl and $\mathrm{PE} 15 \mathrm{Cl}$ this number increases slowly with increasing temperature and sharply upon melting, the content of $\mathrm{TG}$ conformers of $\mathrm{PE9Cl}$ displays the reverse trend, it decreases from $58 \%$ to $\sim 40 \%$ upon heating, indicating that about $85 \%$ of the $\mathrm{C}-\mathrm{CHCl}-\mathrm{C}$ bonds in the crystalline regions are of the $\mathrm{TG}$ type. This value is computed taking the X-ray crystallinity (34\%) and assuming the same TG content in the amorphous region as in the melt. The behavior of the random systems with temperature is equivalent to that of $\mathrm{PE} 21 \mathrm{Cl}$ and $\mathrm{PE} 15 \mathrm{Cl}$. Clearly, the regularity of $\mathrm{Cl}$ placement in the chain and proximity between adjacent $\mathrm{Cl}$ units in $\mathrm{PE} 9 \mathrm{Cl}$ makes packing of chain segments and accommodation of the $\mathrm{Cl}$ atoms in the lattice more restrictive, such that the crystalline order is only perpetuated by chain bends (or kinks) that differ from the otherwise preferred TT structure, thus increasing the overall TG conformation. It then appears that the chain packing of $\mathrm{PE9Cl}$ is conformationally disordered, albeit the crystalline structure is more ordered as discussed later, explaining the differences found in the diffractogram of this sample in reference to the patterns of lower $\mathrm{Cl}$ analogs.

Solid-State NMR. Quantitative information about the distribution of $\mathrm{Cl}$ atoms between crystalline and noncrystalline regions of precision and random EVCs is found by analysis of solid-state NMR resonances of carbons associated with the $\mathrm{Cl}$ substituent in ordered and disordered environments. Directly polarized ${ }^{13} \mathrm{C}$ NMR spectra were obtained with recycle times varying from 150 to $180 \mathrm{~s}$, which correspond to approximately 5 times the spin-lattice relaxation time of crystalline $\mathrm{CH}_{2}$ (the slowest relaxing component). These fully relaxed DD/MAS ${ }^{13} \mathrm{C}$ spectra are shown in Figure 4. From low- to high-field carbon resonances appear at $\sim 65 \mathrm{ppm}$ (methine), $\sim 40 \mathrm{ppm}\left(\mathrm{CH}_{2} \alpha\right.$ to methine), $\sim 30 \mathrm{ppm}$ (internal $\left.\mathrm{CH}_{2}\right)$, and $\sim 27 \mathrm{ppm}\left(\mathrm{CH}_{2} \beta\right.$ to methine). A feature unique to the ADMET synthesis used is the absence of vicinal chlorination and of blocky substituted structures which are characteristic of ethylene vinyl chloride copolymers made by chlorination of polyethylene in suspension or from the bulk. ${ }^{24-26}$ In the latter, multiple stereo sequences 
(a)

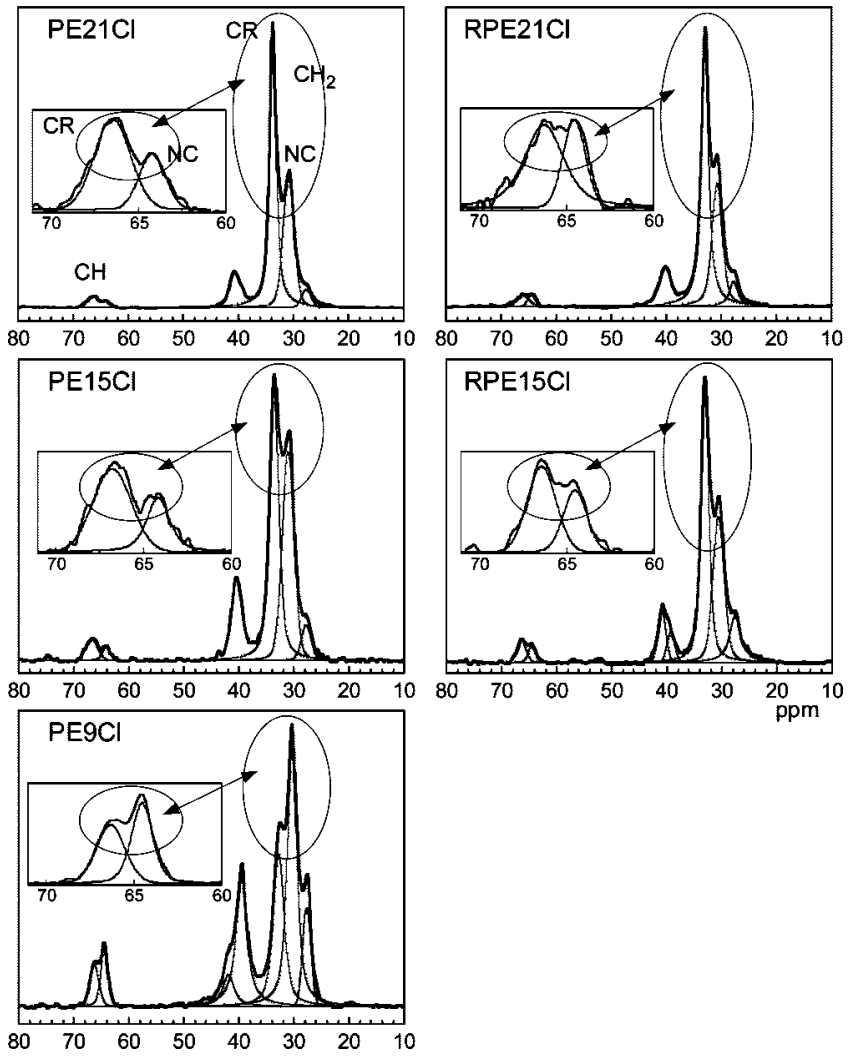

Figure 4. Fully relaxed ${ }^{13} \mathrm{C}$ NMR DD/MAS spectra of Cl-substituted polyethylenes with precise (a) and random (b) distribution. The insets are expansions of the $60-70 \mathrm{ppm}$ spectral regions to guide comparative ratios of crystalline $(\mathrm{CR})$ and noncrystalline (NC) $\mathrm{CH}$ and $\mathrm{CH}_{2}$ resonances, as circled.

Table 3. ${ }^{13} \mathrm{C}$ NMR Chemical Shifts for Crystalline (c) and Noncrystalline (a) Carbons from the DD MAS Spectra of Figure 4

\begin{tabular}{|c|c|c|c|c|c|c|c|}
\hline \multirow[b]{2}{*}{ sample } & \multicolumn{2}{|c|}{$\mathrm{CH}$ (ppm) } & \multicolumn{2}{|c|}{$\alpha-\mathrm{CH}_{2}$} & \multicolumn{2}{|c|}{$\mathrm{CH}_{2}$} & \multirow[b]{2}{*}{$\beta-\mathrm{CH}_{2} \mathrm{a}$} \\
\hline & c & $\mathrm{a}$ & $\mathrm{c}$ & $\mathrm{a}$ & c & $\mathrm{a}$ & \\
\hline PE21Cl & 66.4 & 64.1 & 40.4 & 39.6 & 34.0 & 30.9 & 27.5 \\
\hline PE15Cl & 66.5 & 64.1 & 40.3 & & 33.7 & 30.9 & 27.7 \\
\hline PE9Cl & 66.1 & 64.4 & 41.5 & 39.5 & 32.6 & 30.4 & 27.6 \\
\hline $\mathrm{RPE} 21 \mathrm{Cl}$ & 66.1 & 64.4 & 40.0 & & 33.0 & 30.9 & 27.6 \\
\hline RPE15Cl & 66.2 & 64.5 & 40.8 & 39.2 & 33.1 & 30.7 & 27.6 \\
\hline
\end{tabular}

define the environment of the methine region, resulting in broad ${ }^{13} \mathrm{C}$ NMR $\mathrm{CH}$ resonances not suitable to determine the distribution of $\mathrm{Cl}$ between crystalline and noncrystalline regions. ${ }^{8}$ The precise and isolated nature of the $\mathrm{CHCl}$ group in the ADMET polymers studied here allows a resolved difference in the $\mathrm{CHCl}$ chemical shift between crystalline ( $\sim 66 \mathrm{ppm})$ and noncrystalline phases $(\sim 64 \mathrm{ppm})$ in all samples, as clearly seen in the expanded insets of Figure 4. As expected, there is also a clear resolution of the more abundant crystalline $(\sim 33 \mathrm{ppm})$ and amorphous ( $\sim 30 \mathrm{ppm}) \mathrm{CH}_{2}$ as well as for $\alpha-\mathrm{CH}_{2}(39-41 \mathrm{ppm})$ in most of the spectra. All observed ${ }^{13} \mathrm{C}$ NMR chemical shifts are listed in Table 3. The most significant chemical shift difference between orthorhombic (random) and triclinic (precision) polymers corresponds to the crystalline $\mathrm{CH}_{2}$. The observed value for $\mathrm{RPE} 21 \mathrm{Cl}$ and $\mathrm{RPE} 15 \mathrm{Cl}$ at $33.0 \mathrm{ppm}$ is equivalent to the resonance for all-trans crystalline $\mathrm{CH}_{2}$ in linear polyethylene (32.8 ppm), while this resonance in triclinic PE21Cl and $\mathrm{PE} 15 \mathrm{Cl}$ is shifted $\sim 1$ ppm downfield in analogy to similar shifts found between orthorhombic and triclinic n-alkanes. ${ }^{27}$

Evidence of quantitative spectra is first shown by the ratio of the area of both $\mathrm{CH}$ resonances over the total area (all
Table 4. Quantitative Cl Partitioning Analysis from ${ }^{13} \mathrm{C}$ NMR Spectra of Figure 4

\begin{tabular}{lrccccr}
\hline sample & {$[\mathrm{CH}]^{a}$} & {$[\mathrm{CH}]^{b}$} & heights ratio $^{c}$ & $X_{\mathrm{C}_{\mathrm{CH}}}{ }^{d}$ & $X_{\mathrm{C}_{\mathrm{CH} 2}}{ }^{e}$ & {$[\mathrm{CH}]$ in $\mathrm{CR}^{f}$} \\
\hline PE21Cl & 4.8 & $4.4 \pm 0.2$ & 0.91 & 69 & 70 & $4.1 \pm 0.2$ \\
PE19Cl & 5.3 & $5.0 \pm 0.2$ & 1.01 & 76 & 80 & $4.8 \pm 0.3$ \\
PE15Cl & 6.7 & $6.3 \pm 0.3$ & 1.03 & 63 & 66 & $6.9 \pm 0.2$ \\
PE9Cl & 11.1 & $9.7 \pm 0.5$ & 1.03 & 47 & 46 & $10.3 \pm 0.7$ \\
RPE21Cl & 4.8 & $4.7 \pm 0.3$ & 0.77 & 52 & 69 & $3.3 \pm 0.3$ \\
RPE15Cl & 6.7 & $6.5 \pm 0.3$ & 0.89 & 55 & 64 & $5.4 \pm 0.2$
\end{tabular}

${ }^{a} \mathrm{Mol} \%$ of methine carbons from the primary chain structure. ${ }^{b} \mathrm{Mol} \%$ of methine carbons obtained from the ratio of the methine area $(60-70$ ppm) over all carbons resonance areas $(20-70 \mathrm{ppm}) .{ }^{c}$ Defined as $R_{\mathrm{CH}} /$ $R_{\mathrm{CH}_{2}}$ where $R_{\mathrm{CH}}=I_{\sim 66} / I_{\sim 64}$ and $R_{\mathrm{CH}_{2}}=I_{\sim 33} / I_{\sim 31}$. Uncertainty, \pm 0.1 . ${ }^{d}$ Percent crystallinity obtained from $\mathrm{CH}$ carbon resonances. Uncertainty, \pm 3 . ${ }^{e}$ Percent crystallinity obtained from $\mathrm{CH}_{2}$ carbon resonances. Uncertainty, $\pm 3 .{ }^{f} \mathrm{Mol} \%$ of $\mathrm{CHCl}$ in the crystalline regions (CR).

carbons). This ratio corresponds to the fractional content of $\mathrm{Cl}$ in the chain, which as seen in Table 4 is nearly equivalent to the theoretical value from the primary structure. This close equivalence points out that broadening of the methine resonance due to quadrupolar interactions of the $\mathrm{Cl}$ nuclei is not so strong that methine intensity falls outside the $60-70 \mathrm{ppm}$ region. As the $\mathrm{Cl}$ content increases in the series, the resonances of amorphous $\mathrm{CH}$ and $\mathrm{CH}_{2}$ also increase in intensity, denoting a decrease in crystallinity in agreement with WAXD and heat of fusion data. Furthermore, crystalline and amorphous resonances of $\mathrm{CH}, \alpha-\mathrm{CH}_{2}$, and main $\mathrm{CH}_{2}$, extracted from the spectra from peak deconvolution, were used to obtain information on crystallinity and the distribution of $\mathrm{CHCl}$ in both phases. All quantitative data and experimental uncertainties are listed in Table 4.

We first notice in the NMR spectra of precision polymers (Figure 4a) that the intensity ratio between crystalline and amorphous $\mathrm{CH}\left(\mathrm{R}_{\mathrm{CH}}\right)$ equals the ratio between crystalline and amorphous $\mathrm{CH}_{2}\left(R_{\mathrm{CH}_{2}}\right)$ intensities, indicating equivalence in the distribution of these types of carbons in both phases. This result, also listed in Table 4, is consistent with the expected uniform distribution of $\mathrm{Cl}$ between crystalline and noncrystalline regions for systems that crystallize as homopolymers with no discrimination in packing selected sequences from the chain. Contrary to the behavior of precision systems, the $R_{\mathrm{CH}}$ and $R_{\mathrm{CH}_{2}}$ values of $\mathrm{RPE} 21 \mathrm{Cl}$ and $\mathrm{RPE} 15 \mathrm{Cl}$ are no longer equivalent as highlighted in Figure 4b. In the random polymers, the selection of long methylene sequences during crystallization leads to amorphous regions rich in short sequences. Therefore, the distribution of the $\mathrm{Cl}$ units between the phases is not uniform as seen by $R_{\mathrm{CH}} / R_{\mathrm{CH}_{2}}<1$.

The content of $\mathrm{Cl}$ in the crystalline regions of each sample was computed from the ratio of the crystalline $\mathrm{CH}$ resonance over all crystalline resonances, after peak deconvolution of crystalline and amorphous resonances. ${ }^{28}$ The content of crystalline $\alpha-\mathrm{CH}_{2}$ was obtained by subtracting from the total $\alpha-\mathrm{CH}_{2}$ region the noncrystalline beta $\mathrm{CH}_{2}$ at $\sim 27.5 \mathrm{ppm}$. The intensity of crystalline $\beta-\mathrm{CH}_{2}$, hidden under the internal $\mathrm{CH}_{2}$ amorphous peak, was taken equivalent to the value of crystalline $\alpha-\mathrm{CH}_{2}$.

Extracting the proper intensities of all crystalline carbons for $\mathrm{PE} 9 \mathrm{Cl}$ is complicated by vicinal and $\gamma$-gauche upfield shifts associated with the presence of $\mathrm{C}-\mathrm{CHCl}-\mathrm{C}$ (TG) conformers in the crystalline regions of this sample, as evidenced by the Raman spectra shown in Figures 2 and 3. These shifts were first estimated following the work of Tonelli et al. ${ }^{29}$ According to this work, shielding of a $\mathrm{CH}$ by a substituent that is in a carbon three bonds apart ( $\gamma$ position) from the observed carbon results in an upfield shift of $\sim-2.5$ ppm only when the $\mathrm{CH}-\mathrm{C}$ bond is in a gauche conformation. In addition, the $\alpha-\mathrm{CH}_{2}$ vicinal and in a gauche conformation to the substituted carbon presents a similar upfield chemical shift. ${ }^{30}$ The latter explains the 


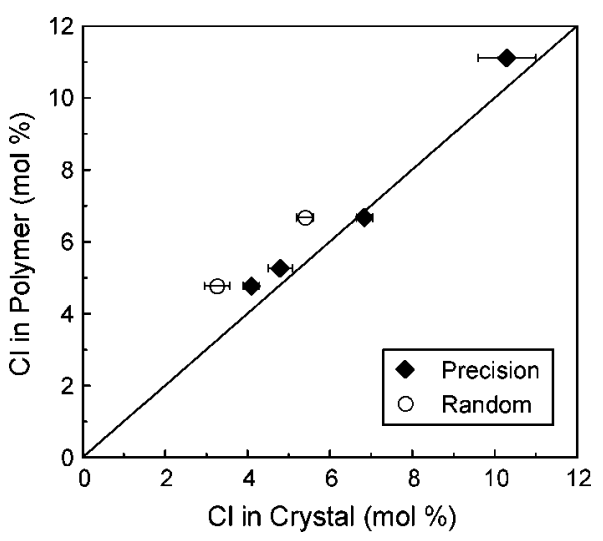

Figure 5. Content of chlorine in the chain against content of chlorine in the crystalline regions evaluated from the ${ }^{13} \mathrm{C}$ NMR DD/MAS spectra of Figure 4 (see text).

apparent low intensity of the crystalline $\alpha-\mathrm{CH}_{2}$ resonance of $\mathrm{PE} 9 \mathrm{Cl}(41.5 \mathrm{ppm})$ in reference to the amorphous intensity (39.5 ppm) in Figure 4a, as compared to the ratio between crystalline and amorphous methine carbons. It is known from the Raman data that about $15 \%$ of all $\mathrm{C}-\mathrm{CHCl}-\mathrm{C}$ crystalline bonds are in all-trans (TT) and $85 \%$ are in TG conformations; consequently, due to the vicinal gauche effect, an upfield shift of $-2.5 \mathrm{ppm}$ is expected for $42 \%$ of the crystalline $\alpha-\mathrm{CH}_{2}$ intensity. As seen in the NMR spectrum of $\mathrm{PE9Cl}$, this shift brings the chemical shift of crystalline $\alpha-\mathrm{CH}_{2}$ carbons from 41.5 to 39 ppm, thus overlapping with the amorphous $\alpha-\mathrm{CH}_{2}$ resonance. As mentioned, this shift explains the apparent high intensity of the latter in the spectrum of PE9Cl. A similar shift to account for $\gamma$-gauche interactions shifts $\sim 20 \%(0.8 \times 1 / 4)$ of the resonance of internal crystalline $\mathrm{CH}_{2}$ from 32.6 to $30.1 \mathrm{ppm}$, which is the region of the chemical shift of amorphous internal $\mathrm{CH}_{2}$. Given that the fraction of $\mathrm{CH}_{2}$ from all internal methylenes subjected to $\gamma$-gauche chemical shift is half the fraction of $\alpha-\mathrm{CH}_{2}$ shifted from vicinal gauche considerations, the effect on the ratio between crystalline to amorphous spectral peak heights is not as prominent as for the $\alpha-\mathrm{CH}_{2}$ peaks ratio.

Chain kinks at the substitution point of $\mathrm{PE9Cl}$ and the small WAXD reflection at $9.5 \AA$ (indicated as an arrow at $2 \theta=9.5^{\circ}$ in Figure 1), which corresponds to a space slightly below the all-trans extended length of the repeat unit (11.4 $\AA$ ), suggest that the $\mathrm{Cl}$ atoms are arranged in the crystalline regions of $\mathrm{PE9Cl}$ in parallel planes, tilted about $55^{\circ}$ with respect to the chain axis. This packing mode is likely to be favored by a preferential folding at the chlorine position, as found in model chlorinated alkanes, ${ }^{31}$ and by the slower crystallization of $\mathrm{PE9Cl}$ compared to precision samples of lower chlorine content. It appears that a fast crystallization in the latter, even under slow cooling at 1 ${ }^{\circ} \mathrm{C} / \mathrm{min}$, prevents this preferential folding at the junction. The result is a more disordered arrangement of $\mathrm{Cl}$ atoms in the crystalline regions of $\mathrm{PE} 21 \mathrm{Cl}, \mathrm{PE} 19 \mathrm{Cl}$, and $\mathrm{PE} 15 \mathrm{Cl}$, which exert distortions to the planar zigzag chain without changing the trans conformation.

Quantitative data for the content of $\mathrm{Cl}$ in the chain, calculated from the combined (crystalline and noncrystalline) $\mathrm{CHCl}$ resonances, and for the content of $\mathrm{Cl}$ in the crystalline regions, using the deconvoluted intensities for crystalline carbons, are listed in Table 4 (third and last columns). For PE9Cl corrections to the observed crystalline intensities for vicinal effects and $\gamma$-gauche interactions were applied after peak deconvolution for this calculation. The content of $\mathrm{Cl}$ in the chain is plotted versus the NMR-calculated content of $\mathrm{Cl}$ in the crystal in Figure 5. There is a one to one relationship of those two quantities for the systems with precise $\mathrm{Cl}$ placement within the experimental uncertainty, giving evidence of a uniform distribution of the content of $\mathrm{Cl}$ between all the phases of the solid systems. The smaller $\mathrm{CR} \mathrm{Cl}$ content obtained for $\mathrm{PE9Cl}$ is justified with the suggested folding at the $\mathrm{Cl}$ position in this sample and the expectation that, as defects, the $\mathrm{Cl}$ atoms in the vicinity of the lamellar surface will be outside of the crystal. For a crystallite of $\sim 90 \AA$ thickness, this consideration will decrease the CR Cl content by $12.5 \%$, i.e., from 11.1 to $9.8 \mathrm{~mol} \%$, thus approaching the NMR observation. However, the content of $\mathrm{Cl}$ in the crystalline regions of the random analogues is lower than the $\mathrm{Cl}$ content in the chain. The crystallinities calculated from $\mathrm{CH}$ or $\mathrm{CH}_{2}$ resonances are the same for precision polymers but differ for the random systems. These results fully support a drastically different crystallization mechanism between substituted polyethylenes with precision or random placement, which was previously inferred from their different melting behavior. ${ }^{13,15,16}$

The equivalence in the distribution of $\mathrm{Cl}$ between crystalline and amorphous regions in the precision systems gives evidence of a crystallization drive led by packing continuous chain segments that accommodate the substituent as a defect. In reference to linear $\mathrm{PE}$, distortions to the lattice by the $\mathrm{Cl}$ substituent cause first a change in the crystallographic packing from the orthorhombic to a triclinic cell, and second, the formation of conformationally disordered, but structurally more ordered, crystallites when the distance between substituents decreases to $\leq 8$ methylenes. Contrasting the homopolymer-like crystallization of precisely substituted polyethylenes, the path to the formation of the crystalline state in the random copolymers is via preferential selection of the most crystalline sequences which are those with the longest continuous methylene runs. In the initial stages of crystal formation, folding and packing of long methylene sequences in an orthorhombic lattice is feasible because the $\mathrm{Cl}$ content included is not sufficient to make this preferential packing unstable; then, growth of the orthorhombic lattice in RPE21Cl proceeds, in spite of transport limitations, due to the availability of sufficiently long methylene sequences. In this selection process, the shorter sequences remain uncrystallized, increasing the concentration of $\mathrm{Cl}$ in this region as confirmed by the NMR results. Differences observed in the melting behavior are consistent with this crystalline pattern. ${ }^{16}$ For instance, while the melting of precisely substituted polymers is very sharp, typical of homopolymers, random analogues melt in a broad temperature range due to the changing melt composition and lead to higher final melting temperatures because the initially formed less defected crystals melt at this final stage. This comparative behavior demonstrates that the placement of the substituent has a major impact on the crystallization behavior of substituted polyethylenes.

Thermodynamic Properties. The X-ray and thermal data are used in this section to obtain thermodynamic $\Delta H^{\circ}, \Delta S^{\circ}$, and $T_{\mathrm{m}}{ }^{\circ}$ quantities of the precision series, which are novel homopolymers with repeating unit, $\left[-\mathrm{CHCl}-\left(\mathrm{CH}_{2}\right)_{x}-\right]_{n}$ for $x$ $=20,18,14$, or 8 methylene units.

The value of $T_{\mathrm{m}}{ }^{\circ}$ was estimated from Hoffman-Weeks $T_{\mathrm{m}}-T_{\mathrm{c}}$ extrapolations for polymers isothermally crystallized at low levels of crystallinity, as shown in Figure 6. The value of the $T_{\mathrm{m}}$ that intercepts with the line $T_{\mathrm{m}}=T_{\mathrm{c}}$ corresponds to the equilibrium melting temperature. These values are listed in Table 5. The slope of the $T_{\mathrm{m}} / T_{\mathrm{c}}$ data is associated with the thickening that the initial nucleus requires to be stable at $T_{\mathrm{c}}$ and to develop into a mature crystallite. With decreasing undercooling (increasing $T_{\mathrm{c}}$ ), one expects formation of thicker crystallites that will further melt at increasingly higher temperatures.

We notice in Figure 6 that the $T_{\mathrm{m}}$ data for PE21Cl, PE19Cl, and $\mathrm{PE} 15 \mathrm{Cl}$ increase very little with increasing $T_{\mathrm{c}}$; the slopes correspond to $0.15,0.12$, and 0.10 , respectively. This feature indicates that for these systems the size of the stable nucleus is nearly independent of $T_{\mathrm{c}}$, which also appears to be in line with 


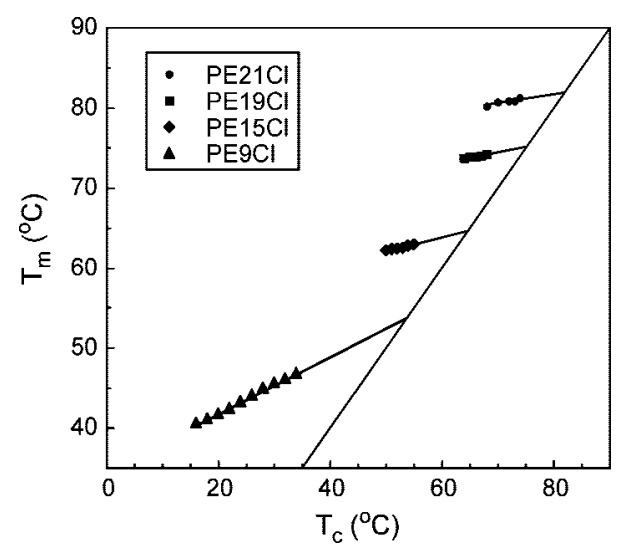

Figure 6. Hoffman-Weeks $T_{\mathrm{m}}$ vs $T_{\mathrm{c}}$ plots to obtain the equilibrium melting temperatures $\left(T_{\mathrm{m}}{ }^{\circ}\right)$ of precision Cl-substituted polyethylenes.

expectations for thickening requirements of crystals with a long $c$ axis in their unit cells, as that found for the triclinic cell of these precisely substituted polymers. For example, the triclinic unit cell of a homopolymer analogous to $\mathrm{PE} 21 \mathrm{Cl}$, with methyl side groups and a similar WAXD pattern, requires a long $c$ axis with a length that spans over two repeating units $(\sim 53 \AA) .{ }^{20} \mathrm{It}$ is thus conceivable that increasing the crystallite thickness along the chain axis requires a significant chain segment length. This may only be found at very low undercoolings, those corresponding to $T_{\mathrm{c}} \mathrm{s}$ too close to $T_{\mathrm{m}}$ for observation of crystallites. This situation is not encountered for $\mathrm{PE} 9 \mathrm{Cl}$ with a $T_{\mathrm{m}}-T_{\mathrm{c}}$ slope of 0.36. A shorter repeat unit and the conformationally disordered nature of the $\mathrm{PE9Cl}$ chain in the crystal allows thickening with increasing $T_{\mathrm{c}}$ and likely isothermal crystalline chain rearrangements to stagger $\mathrm{Cl}$ atoms in crystalline planes.

Also listed in Table 5 are the crystallinities $\left(X_{c}\right)$ obtained from the X-ray diffractograms, which are in very good agreement with crystallinities obtained from the Raman spectra of the same samples. These $X_{\mathrm{c}}$ data are used to correct the DSC heat of fusion $(\Delta H)$ to estimate the value corresponding to the $100 \%$ crystalline specimen $\left(\Delta H^{\circ}\right)$. These values in $\mathrm{J} / \mathrm{mol}$ of repeated unit or in $\mathrm{J} /$ bond in a mole of repeated units are further used with $T_{\mathrm{m}}{ }^{\circ}$ to obtain the entropy change on melting $\left(\Delta S^{\circ}\right)$. We see from these data that $\Delta H^{\circ}$ scales proportionally to the number of $\mathrm{CH}_{2}$ within consecutive $\mathrm{Cl}$ atoms in the series. The value for $\mathrm{PE} 9 \mathrm{Cl}$ is about one-fourth of $\Delta H^{\circ}$ of $\mathrm{PE} 21 \mathrm{Cl}$ denoting that, as the crystals incorporate more chlorines as defects, the energy required to disorder the packing of the backbone repeated unit is dramatically decreased. Both enthalpy $(\mathrm{J} / \mathrm{mol})$ and entropy $(\mathrm{J} /(\mathrm{mol} \mathrm{K}))$ increase with methylene run length of the repeated unit. However, except for PE9Cl the values per single bond remain essentially constant. The reduced $\Delta H^{\circ}$ and $\Delta S^{\circ}$ values per bond for $\mathrm{PE} 9 \mathrm{Cl}$ are associated with the increased conformational disorder in the crystals of this polymer in reference to the all trans packing of higher members of the precision series. Hence, it is clear that the TG crystal disorder found in precisely $\mathrm{Cl}$ substituted polyethylenes at a level of $\sim 10 \mathrm{~mol} \%$ is reflected in their thermodynamic parameters associated with melting. A reduced $\Delta S^{\circ}$ per bond explains the apparent higher melting of $\mathrm{PE} 9 \mathrm{Cl}$ compared to the linear decrease with increasing mol \%

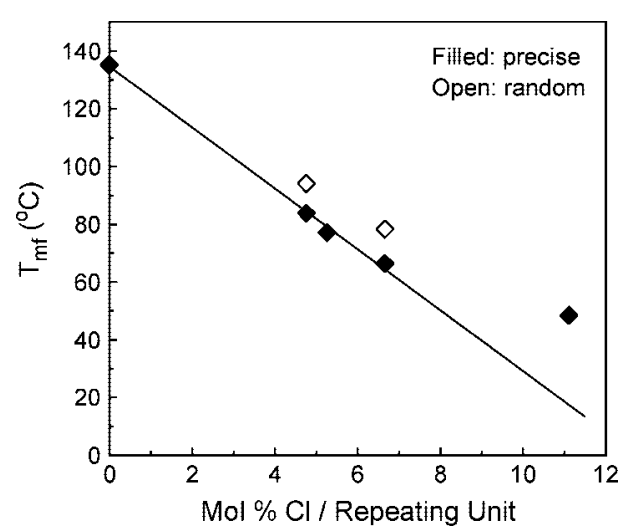

Figure 7. Observed DSC final melting temperatures $\left(T_{\mathrm{mf}}\right)$ as a function of chlorine content for Cl-substituted polyethylenes with precision or random $\mathrm{Cl}$ placement. Data were obtained in samples cooled from the melt to ambient temperature at $1{ }^{\circ} \mathrm{C} / \mathrm{min}$.

$\mathrm{Cl}$ in the members that pack in the all trans conformation, as shown in Figure 7.

Lamellar Morphology and Crystallite Thicknesses. The effect of content and distribution of chlorine on crystalline morphology and structure was obtained from AFM images and SAXS patterns of the same samples slowly cooled at $1{ }^{\circ} \mathrm{C} / \mathrm{min}$. Figure 8 presents topographic $\left(20 \times 20 \mu \mathrm{m}^{2}\right)$ and phase $(4 \times$ 4 and $1.5 \times 1.5 \mu \mathrm{m}^{2}$ ) micrographs to reveal the most notable characteristics of the crystalline morphology of precision (Figure 8a) and random (Figure $8 b$ ) EVC polymers. We first notice the effect of crystallization temperature and kinetics on nucleation density and crystalline evolution during cooling from the melt to room temperature. $\mathrm{PE} 21 \mathrm{Cl}, \mathrm{PE} 19 \mathrm{Cl}$, and $\mathrm{PE} 15 \mathrm{Cl}$ crystallize fast and above room temperature (see $T_{\mathrm{c}}$ values in Table 1 and Figure 4 of ref 13); thus, they develop multiple nuclei and irregular axialitic growth, as observed in the AFM images. On the other hand, the DSC crystallization peak of PE9Cl is 15 ${ }^{\circ} \mathrm{C}$, and therefore, at $T_{\mathrm{c}} \mathrm{s}$ greater than or equal to room temperature the crystallization of $\mathrm{PE9Cl}$ is isothermal and relatively slow. This is the reason for the low number of nuclei and the relatively large spherulites $(15-20 \mu \mathrm{m}$ diameter) developed by PE9Cl.

While the supermolecular morphology differs with increasing chlorine content, the constituent in all types are lamellar stacks, as clearly seen in the phase images at higher resolution. Long and straight lamellae radiating outward from the center of the aggregates are the common lamellar features of precision chlorine containing polymers. It is noteworthy that this is essentially the lamellar morphology previously reported for linear polyethylenes ${ }^{32}$ and other homopolymers ${ }^{33}$ in the same molecular weight range $\left(10000 \mathrm{~g} / \mathrm{mol}<M_{\mathrm{n}}<30000 \mathrm{~g} / \mathrm{mol}\right)$. Straight lamellae can propagate to extensions over $2 \mu \mathrm{m}$, as seen in most images, due to the precise regularity of the substitution and the homopolymer crystallization pattern of these systems. Estimated lamellae thicknesses from the heights of flat-on lamellae $(\mathrm{PE} 21 \mathrm{Cl})$ or widths of edge-on lamellae (PE15Cl and PE9Cl) are 160, 140, and $90 \AA$, respectively. These values are well above the corresponding distances between

Table 5. Thermodynamic Properties of Precision Cl-Substituted Polyethylenes

\begin{tabular}{lcccccccc}
\hline sample & $X_{\mathrm{c}}(\mathrm{WAXD})^{a}$ & $X_{\mathrm{c}}($ Raman $)$ & $\Delta H(\mathrm{~J} / \mathrm{g})^{a}$ & $\Delta H^{\circ}(\mathrm{J} / \mathrm{mol})^{b}$ & $\Delta H^{\circ} / \mathrm{bond}(\mathrm{J} / \mathrm{mol})$ & $T_{\mathrm{m}}{ }^{\circ}\left({ }^{\circ} \mathrm{C}\right)$ & $\Delta S^{\circ}(\mathrm{J} /(\mathrm{mol} \mathrm{K}))^{b}$ & $\Delta S^{\circ} / \mathrm{bond}(\mathrm{J} /(\mathrm{mol} \mathrm{K}))$ \\
\hline PE & 0.83 & 0.82 & 238 & 4014 & 4014 & 145.5 & 9.6 & 9.6 \\
PE21Cl & 0.52 & 0.58 & 120.5 & 76777 & 3656 & 83 & 216 & 176 \\
PE19Cl & 0.53 & 0.57 & 107.6 & 61225 & 3222 & 75 & 9.3 \\
PE15Cl & 0.46 & 0.48 & 95.7 & 51158 & 3411 & 65 & 151 & 10.1 \\
PE9Cl & 0.34 & 0.39 & 38.6 & 18397 & 2044 & 54 & 56 & 6.2
\end{tabular}

${ }^{a}$ Data for samples slowly cooled at $1{ }^{\circ} \mathrm{C} / \mathrm{min}$ to room temperature. ${ }^{b} \mathrm{In} \mathrm{PE}$, the mole is defined as a $\mathrm{CH}_{2}$, whereas for the precision EVC series, the mole is the $\left[\left(\mathrm{CH}_{2}\right)_{x}-\mathrm{CHCl}\right]$ unit. 
(a)
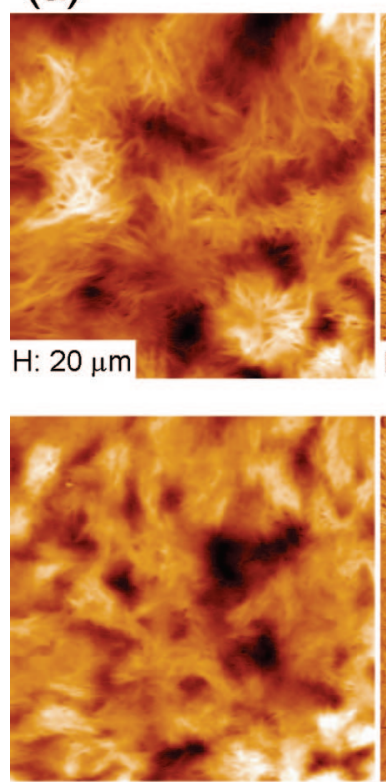

$\mathrm{P}: 4 \mu \mathrm{m}$
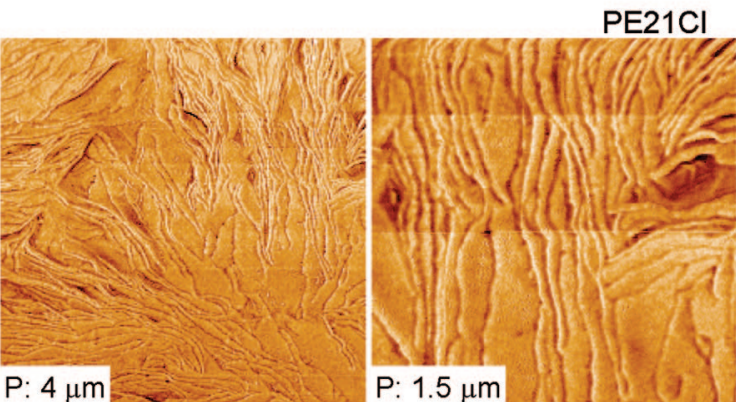

$\mathrm{PE} 15 \mathrm{Cl}$
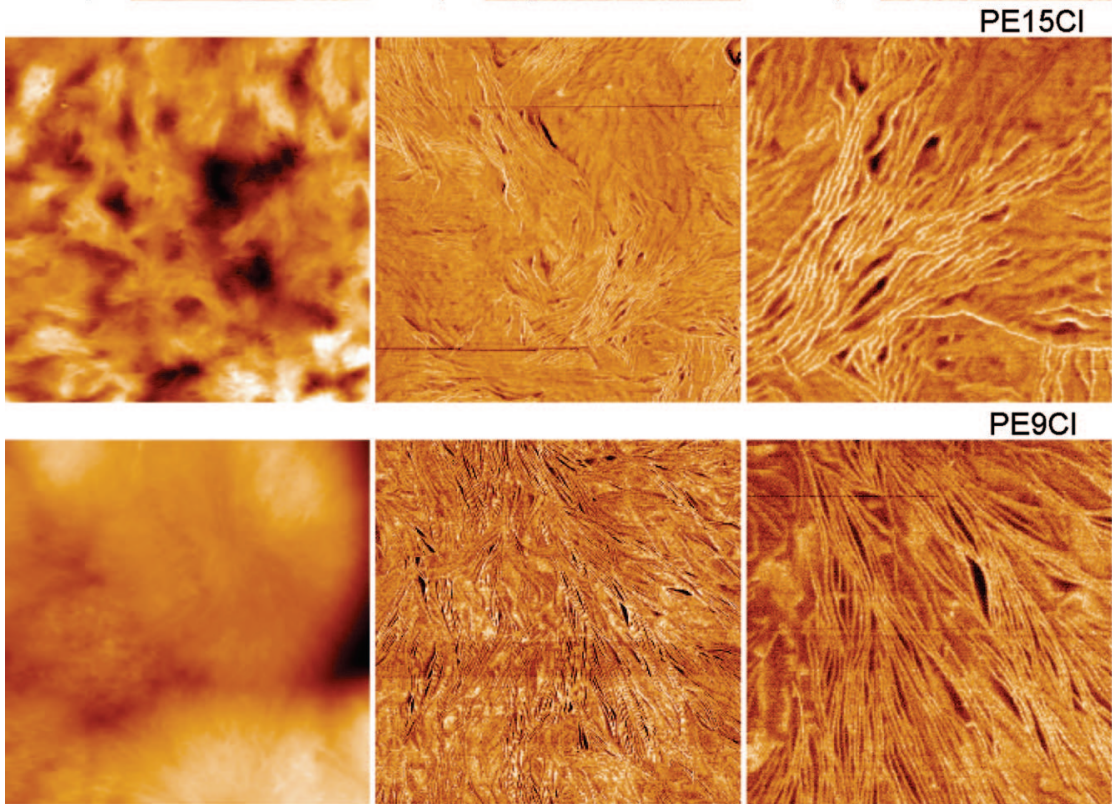

PE9Cl

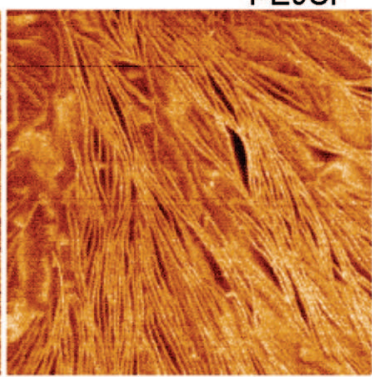

(b)
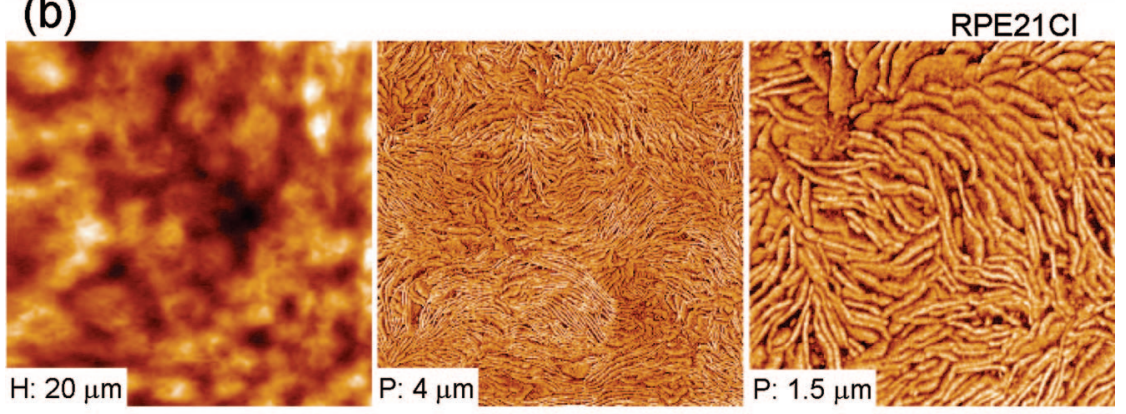

RPE15Cl
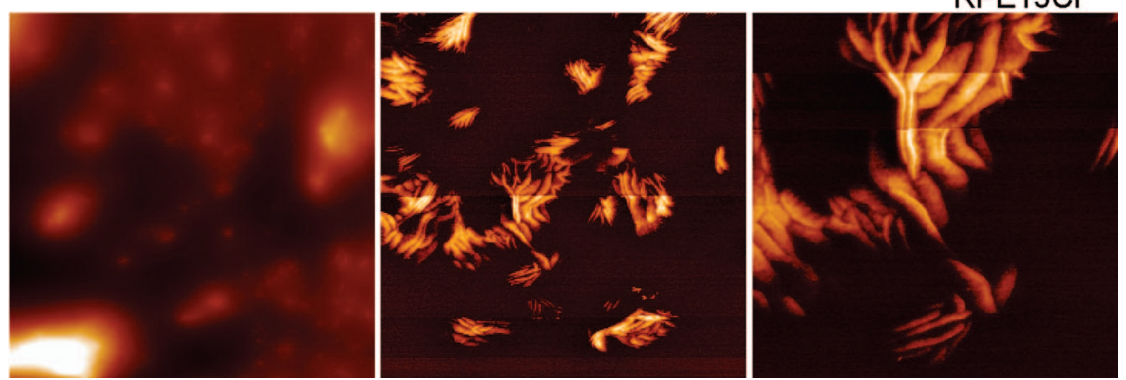

Figure 8. AFM images of Cl-substituted polyethylenes with (a) precise and (b) random $\mathrm{Cl}$ placement, slowly cooled to room temperature from the melt at $1{ }^{\circ} \mathrm{C} / \mathrm{min}$. $\mathrm{H}$ and $\mathrm{P}$ in the insets designate height and phase images, respectively, and the scan size applies to horizontal and vertical scales.

consecutive $\mathrm{Cl}$ atoms in the chain $(25.4,17.8$, and $10.2 \AA)$, and thus give further evidence for the $\mathrm{Cl}$ participation in the lamellae.

The random systems exhibit granular crystal aggregates, which for RPE15Cl were difficult to image due to a rougher film surface. Compared to the straight lamellar features of $\mathrm{PE} 21 \mathrm{Cl}$, those of the random analogs are curved and more segmented, as typical of a copolymer crystallization behavior. Compared to the homopolymer crystallization, the process of crystallizable sequence length selection in random copolymers imposes constraints in transporting through the entangled melt additional sequences to propagate lamellae growth, thus, restricting the extension of the lamellae. Nonetheless, the 

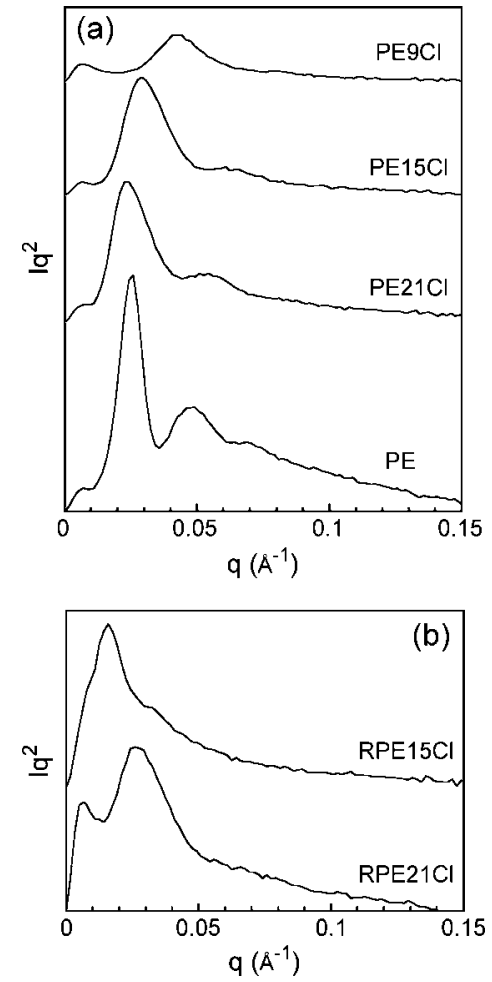

Figure 9. Lorentz-corrected SAXS intensity profiles of linear polyethylene (PE) and Cl-substituted polyethylenes with (a) precise and (b) random distribution.

lamellae of RPE21Cl are thicker $(\sim 145 \AA)$ and more uniform than the poorly formed crystallites developed by random ethylene copolymers containing similar amounts of ethyl branches, which are known to be excluded from the crystals. ${ }^{34}$ These observations give further evidence of a significant $\mathrm{Cl}$ incorporation in the lattice of $\mathrm{RPE} 21 \mathrm{Cl}$ crystallites, thus supporting the conclusions from X-ray and solid-state NMR data.

The crystallite thicknesses obtained by AFM are further compared with average lamellar thicknesses determined by small-angle X-ray scattering (SAXS). Lorentz-corrected and background-subtracted intensity patterns are shown versus scattering vector in Figure 9a (precision) and 9b (random). Precision systems display first- and second-order scattering peaks reflecting a high periodicity of the lamellar stacking, as observed by AFM. The position of the peak maximum $q^{*}$ increases from $q^{*}=0.024$ to $0.043 \AA^{-1}$ with increasing chlorine content, indicating a shorter distance between lamellar stacks, or decreased long spacing, as the content of precisely placed chlorine increases from 4.8 to $11.1 \mathrm{~mol} \%$ in the series. A first estimation of crystalline $\left(l_{\mathrm{c} 1}\right)$ and amorphous layer thicknesses using the Lorentz-corrected long spacing $\left(L_{1}\right)$ and WAXDderived crystallinities $\left(X_{\mathrm{cWAXD}}\right)$, assuming a uniform space-filling model, leads to $l_{\mathrm{c} 1}$ values that decrease with increasing chlorine following the AFM trend. These data are listed in Table 6. The Lorentz-corrected scattering patterns of random analogues shown in Figure 9b have ill-defined second-order reflections and do not show the trend with increasing chlorine content seen in the precision series. This indicates less regularity of lamellar stacks in agreement with the AFM images of these polymers. In fact, the low $q^{*}$ value for RPE15Cl corresponds to $L_{1}=392$ $\AA$ and points to crystal aggregates separated by large regions of noncrystalline material in this polymer. Clearly, the assumed uniform lamellar structure fails for these systems that, as seen in the AFM images, have morphologies not uniformly distributed over the sample volume.
A better estimation of crystalline and amorphous thicknesses of the lamellar stacks in both series was obtained from the onedimensional electron correlation function evaluated in the direction normal to the lamellar stacks. Parameters such as long period $\left(L_{2}\right)$, thickness of the amorphous region $\left(l_{\mathrm{a} 2}\right)$, thickness of the crystalline region $\left(l_{\mathrm{c} 2}=L_{2}-l_{\mathrm{a} 2}\right)$, and linear crystallinity $\left(l_{\mathrm{c} 2} / L_{2}\right)$ were determined following the method of Strobl and Schneider. ${ }^{35}$ The correlation functions for precisely substituted polymers are given in Figure 10, where data for $\mathrm{PE} 19 \mathrm{Cl}$ are omitted for clarity, and the results are listed in Table 6.

The AFM crystallite thicknesses serve to overcome the ambiguity of distinction between the thicknesses of the two layers with different electron densities from the correlation function analysis. The thickness obtained from the selfcorrelation triangle at the first minimum is less than $90 \AA$ and thus corresponds to the amorphous layer.

Illustrated in Figure 11 is the variation of the long period $\left(L_{2}\right)$, amorphous $\left(l_{\mathrm{a} 2}\right)$ and crystal $\left(l_{\mathrm{c} 2}\right)$ thicknesses with increasing chlorine content. We find that while the amorphous layer remains basically constant at $55 \pm 6 \AA$ for precision and random polymers, the long spacing decreases from 236 to $139 \AA$ with increasing $\mathrm{Cl}$ content, leading to a similar trend for the crystallite thickness. $l_{\mathrm{c} 2}$ decreases from 185 to $93 \AA$ in the precision series and are in good agreement with the AFM results. Clearly, the major effect of reducing the number of methylenes between consecutive chlorines in precisely substituted PEs is to decrease the crystallite thickness, while the interlamellar region remains basically constant. The need to accommodate an increasing number of $\mathrm{Cl}$ in the crystal as defects restricts the crystal dimensions in the chain axis.

It is also of interest to comment on the large difference between the crystallinities obtained from WAXD (second column in Table 6) and linear crystallinities obtained from the correlation function (ninth column). While the first decrease rapidly with increasing $\mathrm{Cl}$ content, the crystallinity within stacks shows little change within the series and are 30-50\% higher than $X_{\mathrm{cWAXD}}$. The difference correlates with the AFM morphological features that gave evidence for interspherulitic regions devoid of crystalline structure. Given the nonuniformity of lamellar stacks over the complete sample volume, agreement between $l_{\mathrm{c} 1}$, obtained under the assumption of an ideal stack model, and $l_{\mathrm{c} 2}$ is not expected, as the data of Table 6 reflect.

The results for the random systems point to an interesting comparison of crystal thickness and melting behavior with data for precision analogs. We found that random RPE21Cl melts at a temperature $7{ }^{\circ} \mathrm{C}$ higher than the precision analogue but its crystal thickness is $40 \AA$ lower (table 6, SAXS data). The difference in melting is due to the different mechanism of crystal formation. The selection of the most crystallizable sequences in the random leads to a population of crystals with broad chlorine composition. Those with the lowest chlorine content melt last and at temperatures higher than the melting temperature of crystals formed from precision polymers, which are generated on the basis of homopolymer crystallization, and thus have a higher content of defects. However, while the melting temperature of the random polymers reflects the purity of the crystals and the composition of the melt, the crystal thickness measured by SAXS reflects the average crystalline sequence length during the selection process of the crystallization. The lower limit of this sequence length is set by thermodynamic requirements to form a stable crystallite, and is a decreasing function of undercooling $\left(T_{\mathrm{m}}{ }^{\mathrm{o}}-T_{\mathrm{c}}\right){ }^{36,37}$ An estimation of $T_{\mathrm{m}}{ }^{\circ}$ for RPE21Cl using the Sanchez-Eby equation ${ }^{38}$ gives $139.4{ }^{\circ} \mathrm{C}$, which is significantly higher than the $T_{\mathrm{m}}{ }^{\circ}$ value for $\mathrm{PE} 21 \mathrm{Cl}$ of $83{ }^{\circ} \mathrm{C}$ (Table 5). These data suggest that during the slow cooling crystallization the average undercooling for the formation of crystals from the random systems is much higher than for 
Table 6. Structural Parameters Obtained from SAXS of Crystalline Linear PE and Cl-Substituted Polyethylenes with Precision or Random Cl Placement

\begin{tabular}{|c|c|c|c|c|c|c|c|c|c|}
\hline \multirow[b]{2}{*}{ sample $^{a}$} & \multicolumn{4}{|c|}{ Lorentz correction } & \multicolumn{4}{|c|}{ correlation function } & \multirow[b]{2}{*}{$\operatorname{AFM} l_{\text {cAFM }}(\AA)^{h}$} \\
\hline & $X_{\text {cWAXS }}(\%)$ & $q_{1}\left(\AA^{-1}\right)$ & $L_{1}(\AA)^{b}$ & $\overline{l_{\mathrm{c} 1}(\AA)^{c}}$ & $L_{2}(\AA)^{d}$ & $l_{\mathrm{a} 2}(\AA)^{e}$ & $l_{\mathrm{c} 2}(\AA)^{f}$ & $X_{\mathrm{c} 2}(\%)^{g}$ & \\
\hline $\mathrm{PE}$ & 83 & 0.0260 & $242 \pm 5$ & 201 & $250 \pm 5$ & 40 & 210 & 84 & \\
\hline $\mathrm{PE} 21 \mathrm{Cl}$ & 52 & 0.0244 & $258 \pm 5$ & 134 & $236 \pm 7$ & 51 & 185 & 78 & $160 \pm 17$ \\
\hline $\mathrm{PE} 19 \mathrm{Cl}$ & 53 & 0.0294 & $214 \pm 7$ & 113 & $220 \pm 5$ & 53 & 167 & 73 & \\
\hline $\mathrm{PE} 15 \mathrm{Cl}$ & 46 & 0.0294 & $214 \pm 5$ & 98 & $200 \pm 5$ & 57 & 143 & 71 & $140 \pm 12$ \\
\hline $\mathrm{PE9Cl}$ & 34 & 0.0427 & $147 \pm 3$ & 50 & $139 \pm 3$ & 46 & 93 & 67 & $90 \pm 7$ \\
\hline RPE21Cl & 46 & 0.0260 & $241 \pm 5$ & 111 & $207 \pm 5$ & 61 & 146 & 71 & $145 \pm 15$ \\
\hline $\mathrm{RPE} 15 \mathrm{Cl}$ & 42 & 0.0160 & $392 \pm 10$ & 165 & $i$ & & & & \\
\hline
\end{tabular}

${ }^{a}$ Samples cooled from the melt to room temperature at $1{ }^{\circ} \mathrm{C} / \mathrm{min} .{ }^{b}$ Long spacing $\left(2 \pi / q_{1}\right){ }^{c}$ Lamellar thickness $\left(L_{1} \cdot X \mathrm{c}_{\mathrm{WAXs}}\right){ }^{d}$ Long spacing as first maximum of the correlation function. ${ }^{e}$ Amorphous layer thickness from the self-correlation at the first minimum as detailed in Strobl et al. ${ }^{35} f$ Crystallite thickness $\left(L_{2}-l_{\mathrm{a} 2}\right) .{ }^{g}$ Percent crystallinity within stacks $\left(l_{\mathrm{c} 2} / L_{2}\right) \times 100 .{ }^{h}$ Crystallite thickness from AFM images. ${ }^{i}$ Not analyzed due to ill-defined AFM lamellar stacking.

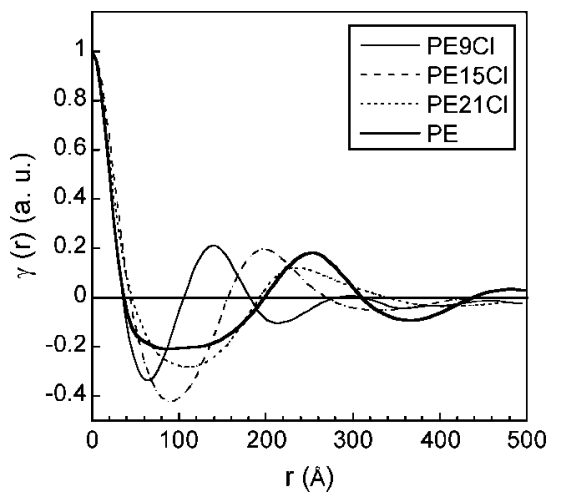

Figure 10. One-dimensional correlation function of linear polyethylene (PE) and precision Cl-substituted polyethylenes.

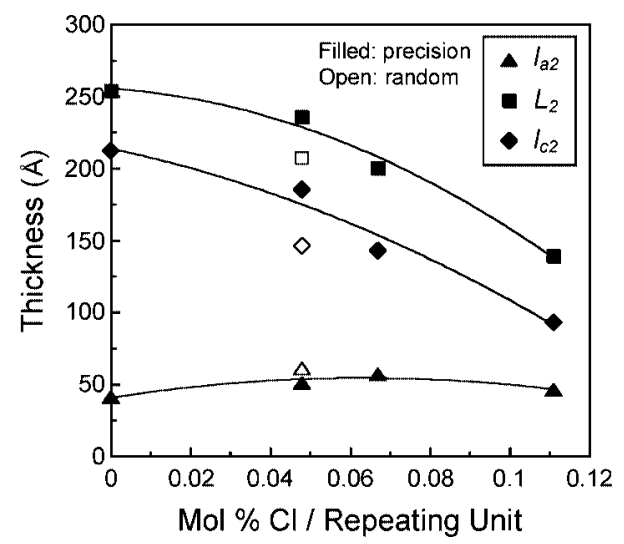

Figure 11. Long spacing $\left(L_{2}\right)$ and thicknesses of amorphous $\left(l_{\mathrm{a} 2}\right)$ and crystalline regions $\left(l_{\mathrm{c} 2}\right)$ as a function of mol \% $\mathrm{Cl}$ obtained for a linear polyethylene (PE) and Cl-substituted polyethylenes with precision and random distribution. The structural data were obtained from the correlation function analysis of SAXS intensities. Lines are drawn to guide data corresponding to precision samples.

precision analogues and provides an explanation for the lower crystal thickness. Therefore, a crystal formation mechanism that leads to high undercoolings and a broader distribution of crystal thicknesses in the random systems explains their thinner crystallites and higher melting with respect to precision analogues.

\section{Conclusions}

A combination of wide and small-angle X-ray scattering, solid-state NMR, Raman spectroscopy, and AFM have been instrumental in addressing the following:

(1) The effect of a precise $\mathrm{Cl}$ placement over a random distribution on the formation of the crystalline state of $\mathrm{Cl}$ substituted polyethylenes.
(2) Differences in the crystalline structure and the distribution of $\mathrm{Cl}$ atoms within the crystalline regions in both random and precision systems.

(3) Equilibrium melting temperatures and heats of fusion of novel polyolefins with repeated structural unit $-\left[(\mathrm{CH} 2)_{x}-\right.$ $\mathrm{CHCl}]_{n}-$ (for $x=8,14,18$, or 20 ).

Quantitative DD MAS solid-state ${ }^{13} \mathrm{C}$ NMR spectra, sharp thermal transitions, and relatively thick crystallites provide evidence for a homopolymer-like crystallization of all precisely substituted polymers studied. The inclusion of the $\mathrm{Cl}$ as a defect in the crystal while folding and packing chain segments renders strains in the lattice to a level such that the orthorhombic unit cell of the linear PE crystal is not stable in these systems. This crystallization mechanism appears to be general for all substituted and branched precision polyethylenes provided the side group can be accommodated in a stable lattice. In contrast, the nonuniform distribution of $\mathrm{Cl}$ between crystalline and noncrystalline regions of the random systems, coupled with broader peaks and higher final meltings than those of precision analogues, indicates a crystallization mechanism driven by the preferential selection of the most crystallizable long methylene sequences. This is supported by the formation of orthorhombic unit cells, as shown by WAXD and Raman spectroscopy.

The crystal aggregates, or supermolecular morphology, of precision and random systems differ according to their crystallization mode. The homopolymers display larger, better arranged, structures (axialites or spherulites) than random (granular) counterparts. Moreover, the constituents of all aggregates are lamellar stacks. Lamellae are long and straight for precision polymers due to the regularity of the substitution and the homopolymer crystallization pattern. The defect nature of the $\mathrm{Cl}$ atom in the $\mathrm{PE}$ chain restricts crystallinity, varying from 80 to $\sim 30 \%$, and also the crystal thickness that changes from $\sim 180$ to $90 \AA$ with increasing $\mathrm{Cl}$ content in the precision series. In contrast, random analogs form curved and segmented lamellae typical of the morphologies of similar types of ethylene-based copolymers.

Conformations other than the preferential TT crystal packing are found in precisely $\mathrm{Cl}$-substituted polyethylenes at a $\mathrm{Cl}$ level $>\sim 10 \mathrm{~mol} \%$. Under relatively slow crystallizations, the $\mathrm{Cl}$ atoms within the crystalline regions of $\mathrm{PE} 9 \mathrm{Cl}$ are arranged in layers tilted $\sim 55^{\circ}$ with respect to the chain axis. This close staggering, driven by a symmetry increase and by minimizing packing volume, leads to chain kinks (crystal TG conformers) at the substitution point. Crystal disorder is reflected in the thermodynamic quantities associated with melting.

Acknowledgment. Funding of this work by the National Science Foundation, DMR-0503876, PREM DMR-0351770, and CTS-0521079, is gratefully acknowledged. We also gratefully acknowledge the assistance of Dr. E. Lockner of MARTECH at 
FSU with X-ray measurements and Drs. R. Fu and F. Nozirov of the NHMFL at Tallahassee with solid-state NMR.

\section{References and Notes}

(1) Alamo, R. G.; Mandelkern, L. Thermochim. Acta 1994, 238, 155.

(2) Krishnaswamy, R. K.; Yang, Q.; Fernandez-Ballester, L.; Kornfield, J. A. Macromolecules 2008, 41, 1693.

(3) Wang, H. P.; Khariwala, D. U.; Cheung, W.; Chum, S. P.; Hiltner, A.; Baer, E. Macromolecules 2007, 40, 2852.

(4) Scheirs, J., Kaminski, W., Eds.; Metallocene-based PolyolefinsPreparation, Properties and Technology; Wiley: New York, 2000; Vol. 1 and 2 .

(5) Bubeck, R. A. Mater. Sci. Eng. Rev. 2002, 39, 1.

(6) Brintzinger, H. H.; Fischer, D.; Mülhaupt, R.; Rieger, B.; Waymouth, R. Angew. Chem., Int. Ed. Engl. 1995, 34, 1143.

(7) Ivin, K. J.; Mol, J. C. Olefin Metathesis and Metathesis Polymerization; Academic Press: San Diego, CA, 1997.

(8) Gomez, M. A.; Tonelli, A. E.; Lovinger, A. J.; Schilling, F. C.; Cozine, M. H.; Davis, D. D. Macromolecules 1989, 22, 4441.

(9) Harrison, I. R.; Baer, E. J. Polym. Sci. A-2 1971, 9, 1305.

(10) Hu, W.; Srinivas, S.; Sirota, E. Macromolecules 2002, 35, 5013.

(11) Alamo, R. G.; Domszy, R. C.; Mandelkern, L. J. Phys. Chem. 1984, $88,6587$.

(12) Boz, E.; Nemeth, A. J.; Wagener, K. B.; Jeon, K.; Smith, R.; Nazirov, F.; Bockstaller, M. R.; Alamo, R. G. Macromolecules 2008, 41, 1647.

(13) Boz, E.; Nemeth, A. J.; Ghiviriga, I.; Jeon, K.; Alamo, R. G.; Wagener, K. B. Macromolecules 2007, 40, 6545.

(14) Boz, E.; Nemeth, A. J.; Alamo, R. G.; Wagener, K. B. Adv. Synth. Catal. 2007, 349, 137.

(15) Boz, E.; Wagener, K. B.; Ghosal, A.; Fu, R.; Alamo, R. G. Macromolecules 2006, 39, 4437.

(16) Boz, E.; Ghiviriga, I.; Nemeth, A. J.; Jeon, K.; Alamo, R. G.; Wagener, K. B. Macromolecules 2008, 41, 25.

(17) Vonk, C. G.; Kortleve, G. Kolloid-Z. Z. Polym. 1967, 19, 220.

(18) Stephens, C. H.; Yang, H.; Islam, M.; Chum, S. P.; Rowan, S. J.; Hiltner, A.; Baer, E. J. Polym. Sci., Part B: Polym. Phys. 2003, 41, 2062.
(19) Sworen, J. C.; Smith, J. A.; Wagener, K. B.; Baugh, L. S.; Rucker, S. P. J. Am. Chem. Soc. 2003, 125, 2228.

(20) Lieser, G.; Wegner, G.; Smith, J. A.; Wagener, K. B. Colloid Polym. Sci. 2004, 282, 773.

(21) Shipman, J. J.; Folt, V. L.; Krimm, S. Spectrochim. Acta 1962, 18, 1603.

(22) Robinson, M. E. R.; Bower, D. I.; Maddams, W. F. Polymer 1978, 19, 773.

(23) Stoeva, S. J. Appl. Polym. Sci. 2004, 94, 189.

(24) Sobottka, J. Acta Polym. 1983, 34, 647.

(25) Zhikuan, C.; Lianghe, S.; Sheppard, R. N. Polymer 1984, 25, 369.

(26) Saito, T.; Matsumura, Y.; Hayashi, S. Polym. J. 1970, 1, 639.

(27) VanderHart, D. L. J. Magn. Reson. 1981, 44, 117.

(28) The true CR and amorphous line shapes of the methine resonance may not be symmetrical due to quadrupolar interactions of the $\mathrm{Cl}$ nuclei, i.e. the ${ }^{13} \mathrm{C}-{ }^{35,37} \mathrm{Cl}$ dipolar interaction are not averaged out by magic angle spinning. In view of the fact that the true line shapes are unknown, we have chosen to deconvolute the area of this region with mixed Lorentzian and Gaussian functions using a nonlinear leastsquares method.

(29) Tonelli, A. E.; Schilling, F. C. Macromolecules 1984, 17, 1946.

(30) Tonelli, A. E.; Schilling, F. C. Acc. Chem. Res. 1981, 14, 233.

(31) Gutzler, F.; Wegner, G. Colloid Polym. Sci. 1980, 258, 776.

(32) Voigt Martin, I. G.; Fischer, E. W.; Mandelkern, L. J. Polym. Sci., Part B: Polym. Phys. 1980, 18, 2347.

(33) Bassett, D. C. Principles of Polymer Morphology; Cambridge University Press: New York, 1981.

(34) Alamo, R. G.; Chan, E. K. M.; Mandelkern, L.; Voigt-Martin, I. G. Macromolecules 1992, 25, 6381.

(35) Strobl, G.; Schneider, M. J. J. Polym. Sci., Polym. Phys. Ed. 1980, $18,143$.

(36) Mandelkern, L.; Fatou, J. G.; Howard, C. J. Phys. Chem. 1965, 69, 956.

(37) Jeon, K.; Chiari, Y. L.; Alamo, R. G. Macromolecules 2008, 41, 95.

(38) Sanchez, I. C.; Eby, R. K. Macromolecules 1975, 8, 638.

MA801152P 